\title{
Strategies for Optimizing Growth in Children With Chronic Kidney Disease
}

\begin{abstract}
Dieter Haffner*
Department of Pediatric Kidney, Liver and Metabolic Diseases, Hannover Medical School Children's Hospital, Hanover, Germany
\end{abstract}

Growth failure is a hallmark in children with chronic kidney disease (CKD). Therefore, early diagnosis and adequate management of growth failure is of utmost importance in these patients. The risk of severe growth retardation is the higher the younger the child is, which places an additional burden on patients and their families and hampers the psychosocial integration of these children. Careful monitoring of growth, and effective interventions are mandatory to prevent and treat growth failure in children with CKD at all ages and all stages of kidney failure. Early intervention is critical, as all therapeutic interventions are much more effective if they are started prior to the initiation of dialysis. Prevention and treatment of growth failure focuses on: (i) preservation of renal function, e.g., normalization of blood pressure and proteinuria by use of inhibitors of the renin-angiotensin aldosterone system, (ii) adequate energy intake, including tube feeding or gastrostomy in case of persisting malnutrition, (iii) substitution of water and electrolytes, especially in children with renal malformation, (iv) correction of metabolic acidosis, (v) control of parathyroid hormone levels within the CKD-dependent target range, (vi) use of recombinant human growth hormone in cases of persistent growth failure, and, (vii) early/preemptive kidney transplantation using steroid-minimizing immunosuppressive protocols in children with end-stage CKD. This review discusses these measures based on recent guidelines.

Keywords: chronic kidney disease, children, growth, growth hormone, nutrition, CKD-MBD

\section{INTRODUCTION}

Growth failure is a hallmark of children with chronic kidney disease (CKD). Although height prognosis has improved considerably in recent decades, $\sim 40 \%$ of children requiring kidney replacement therapy before puberty continue to achieve a reduced adult height $(<-2 \mathrm{SD})(1-8)$. The risk of severe growth retardation is the higher the younger the child is, which places an additional burden on patients and hampers their psychosocial integration (9). In addition, short stature is associated with markedly enhanced mortality, supporting the concept that normal longitudinal growth is a sensitive indicator of overall well-being in these patients (10-12).

The pathogenesis of short stature in CKD is multifactorial. Chronic kidney disease may be caused by acquired or congenital kidney abnormalities, that manifest themselves in early or late childhood and vary greatly in severity and rate of progression. Similarly, a broad spectrum of concomitant complications (e.g., poor nutritional intake, metabolic acidosis, and electrolyte 
disturbances), as well as CKD- associated growth hormone (GH) insensitivity, has to be considered (Figure 1). While some factors, such as nutritional and hormonal abnormalities, hematological and metabolic disorders, such as electrolyte imbalance, acidosis, mineral and bone disorder (CKD-MBD) and anemia are potentially correctable, the effects of others, birth parameters, associated syndromes and parental height, are not (14). A major breakthrough in the management of uremic growth failure is the introduction of recombinant human growth hormone (rhGH), which overcomes CKD-associated GH insensitivity and thereby increases growth outcome in children with CKD (15). A detailed review on growth and nutrition in pediatric CKD was recently published in this journal (16). This article discusses the main measures to optimize growth in children with CKD during the various stages of kidney disease, i.e., prior to dialysis, on dialysis, and after kidney transplantation, based on published guidelines.

\section{MONITORING}

Adequate monitoring of growth in children with CKD matters. Height in these children may rapidly descend across the percentiles, especially during periods of expected high growth rates, i.e., infancy, early childhood and adolescence. In fact, height losses of up to $1.0 \mathrm{SD}$ per year were reported in infants on dialysis (17). "As with any child who has a potentially growth-limiting chronic disease, length (up to the age of 2 years) and height (from 2 years) should be regularly evaluated by trained personnel, using calibrated equipment and standardized techniques" (13). Anthropometric data should be compared with gender- and age-specific reference values for healthy children. The gestational age should be taken into account in assessing the length of prematurely born infants. Young children and those with more advanced CKD should be seen more often than older children and those with only mild kidney function impairment (Table 1). "Children with evidence of growth retardation, comorbidities, including central nervous system or involvement of the liver or heart, require more frequent assessment than those with a milder or more stable disease" (13). "The calculation of annual height velocity allows for identification of children with reduced growth rates, i.e., below the 25th percentile, and thus identifies children, who may benefit from growth-promoting measures (vide infra)" (13). "By contrast, a height velocity above the 75th percentile indicates catch-up growth" (13). Current national growth charts should be referred to. Alternatively, regional as well as international growth charts may be used. As with any child, growth potential is related to parental height and the genetic target

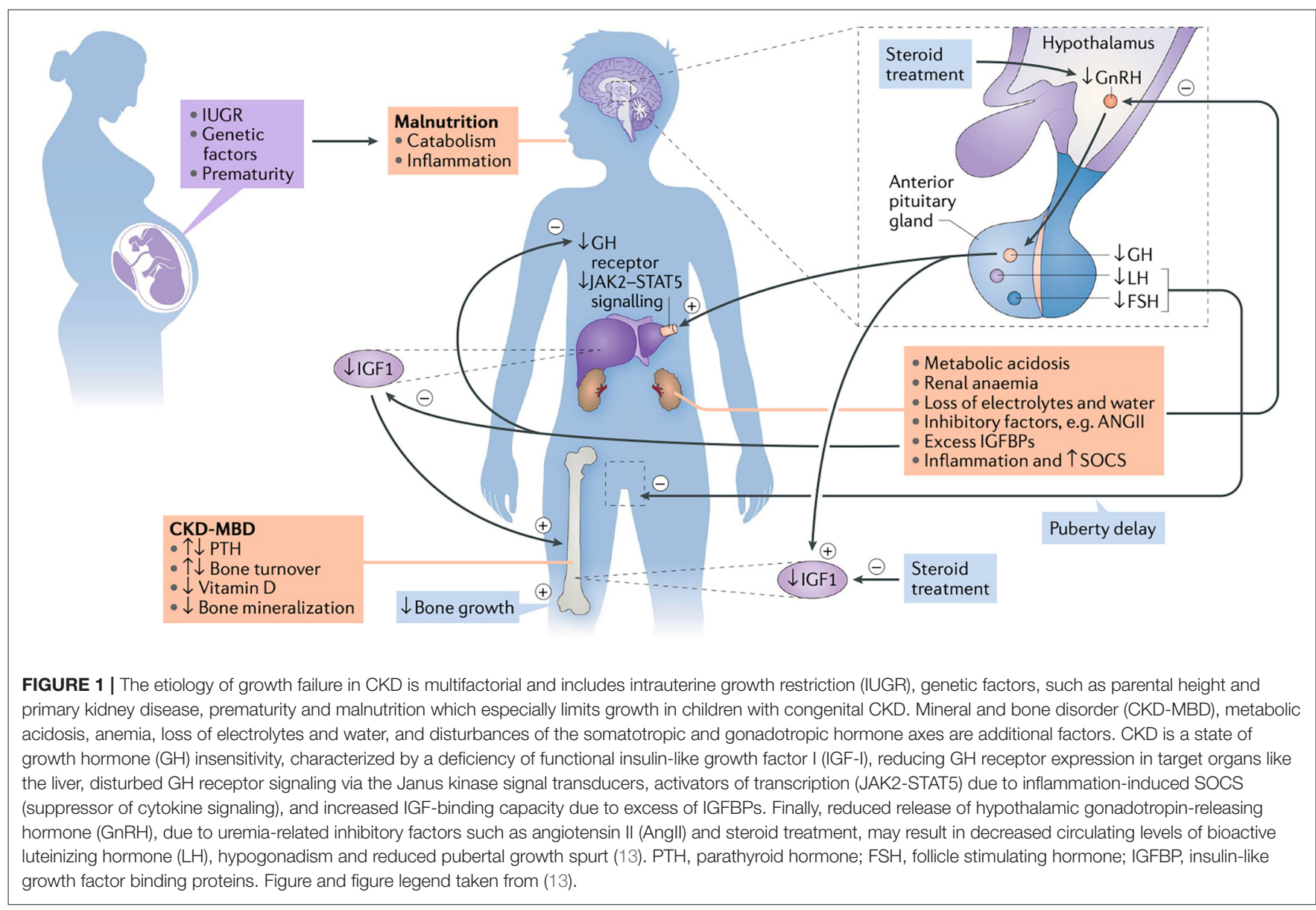


TABLE 1 | Recommended assessment intervals (in months) of length/height and length/height velocity by CKD stage and age.

\begin{tabular}{lcccc}
\hline & \multicolumn{4}{c}{ CKD stage } \\
\cline { 2 - 5 } & $\mathbf{3}$ & $\mathbf{4}$ & $\mathbf{4 - 5}$ & $\mathbf{5 D}$ \\
\hline Length/height & & & & \\
Age 0-1 years & $0.5-2$ & $0.5-2$ & $0.5-2$ & $0.5-2$ \\
Age 1-3 years & $1-3$ & $1-2$ & $1-2$ & $1-2$ \\
Age >3 years & $3-6$ & $1-3$ & $1-3$ & $1-3$ \\
Length/height velocity & & & & $0.5-1$ \\
Age 0-1 years & $0.5-2$ & $0.5-2$ & $0.5-2$ & $1-2$ \\
Age 1-3 years & $1-6$ & $1-3$ & $1-3$ & 6 \\
Age $>$ 3 years & 6 & 6 & 6 & \\
\hline
\end{tabular}

CKD, chronic kidney disease; table taken from (13).

height should be calculated using Tanner's formula for girls and boys:

$$
\begin{aligned}
& \text { Girls : }\left(\text { height }_{\text {mother }}+\text { height }_{\text {father }}-13\right) / 2 \\
& \text { Boys : }\left(\text { height }_{\text {mother }}+\text { height }_{\text {father }}+13\right) / 2
\end{aligned}
$$

These formulas should not be used in cases of parents with chronic disease, whose height may be impaired. Unfortunately, the application of height predicting models based on bone age cannot be recommended in children with $\mathrm{CKD}$, as they, largely, overestimate adult height (18).

\section{PREVENTION AND TREATMENT Preservation of Renal Function and Dialysis}

Growth retardation is rarely seen in CKD stages 1-2, often noted in $\mathrm{CKD}$ stages above 3 , and is generally more pronounced in children on dialysis, compared to patients prior to dialyis (19). This may, at least partly, be due to the negative association between GH-insensitivity and glomerular filtration rate (GFR) (20). The logical consequence of these findings is to keep up GFR rates and provide adequate dialysis in children requiring maintenance dialysis (Table 2). Preservation of renal function requires treatment of elevated blood pressure, with the goal of blood pressure values below the 50th and 75th percentile in proteinuric and non-proteinuric children, respectively (24). Renin-angiotensin aldosterone system inhibitors, preferentially angiotensin-converting enzyme inhibitors or angiotensin receptor inhibitors, should be used to treat high blood pressure and ameliorate proteinuria in children with $\operatorname{CKD}(25,26)$. Nephrotoxic medication should be avoided, and urinary tract infections in children with congenital abnormalities of the kidneys and urinary tract (CAKUT) should be treated.

There is increasing evidence that intensified dialysis, achieved either through extended thrice weekly, nocturnal or short daily sessions, are effective measures to improve growth in short children presenting with persistent growth failure while on conventional dialysis $(27,28)$. In addition, a recent non-randomized study demonstrated superior growth in children treated with hemodiafiltration compared to those
TABLE 2 | Main measures for prevention and treatment of growth failure in pediatric CKD.

Prevention:

- Close growth monitoring with intervals depending on previous growth, age and stage of CKD.

- Preserve renal function by:

- Treating elevated blood pressure and reducing proteinuria, preferrably using RAAS inhibitors.

- Avoiding nephrotoxic medication.

- Prompt treatment of urinary tract infections.

- Provide adequate energy and protein intake and consultation with a renal dietician.

- "Consider enteral feeding by gastrostomy or nasogastric tube in cases of persistent insufficient oral intake" (21).

- Substitute water and electrolyte losses and correct metabolic acidosis.

- "Keep PTH levels in the recommended CKD stage-dependent target range and substitute native vitamin D in cases of low vitamin D levels" $(22,23)$.

- Aim for early (preemptive) renal transplantation with minimal steroid exposure in patients with end-stage CKD.

- Provide adequate dialysis in patients requiring maintenance dialysis.

Treatment:

- "Consider use of growth hormone treatment in cases of persistent growth failure, i.e., height $<3 r d$ percentile and height velocity $<25$ th percentile, excluding patients who have received a transplant within the last 12 months" (13).

- "Consider intensified dialysis or hemodiafiltration in in patients requiring maintenance dialysis presenting with persistent growth failure" (13).

- "Consider use of rhGH therapy in pediatric kidney transplant recipients for whom expected catch-up growth cannot be achieved by steroid minimization, or for patients where steroid withdrawal is not feasible due to high immunological risks, particularly in children with suboptimal graft function (GFR $<50 \mathrm{ml} / \mathrm{min} / 1.73 \mathrm{~m}^{2}$ )" (13).

CKD, chronic kidney disease; RAAS, renin-angiotensin aldosterone system; PTH, parathyroid hormone.

with conventional hemodialysis (29). "Therefore, initiation of intensified dialysis or hemodiafiltration should be considered in children on maintenance dialysis presenting with persistent growth failure" (13).

\section{Nutrition}

The assurance of adequate caloric intake is of major importance to prevent CKD-associated growth failure, especially in infants and young children (21). This requires the patient and families to be advised by a renal dietician, especially when supplementary feeding via a nasogastric or gastrostomy tube is required (21). Physicians should be proactive in instituting tube feeding in any infant or young child not achieving adequate energy intake, as this may result in suboptimal growth outcome (21). "In general, the initial prescription for energy intake in children with CKD should approximate that of healthy children of the same age (suggested dietary intake, SDI)" (21). "To optimize growth in children with suboptimal weight gain and linear growth, energy intake should be adjusted toward the higher end of the SDI" (21). "In addition; to promote optimal growth, target protein intake in children with CKD should be at the upper end of the SDI" (21).

\section{Correction of Acid-Base/Electrolyte Abnormalities}

Metabolic acidosis is associated with poor growth in children with CKD. Therefore, metabolic acidosis should be corrected 
aiming for serum bicarbonate levels equal to or above $22 \mathrm{mEq} / \mathrm{L}$. This can be assured by treatment with sodium bicarbonate and/or the use of $\mathrm{HCO}_{3}$-based or lactate-based dialysis solutions in patients on dialysis (30). Supplementation of water and/or electrolytes is often required in poliuric patients and those with salt-losing nephropathies. It is important to note, that young children on peritoneal dialysis often require supplementation with large amounts of sodium chloride, since considerable losses (i.e., $2-5 \mathrm{mmol} / \mathrm{kg}$ body weight) via peritoneal ultrafiltration may occur.

\section{Treatment of Renal Osteodystrophy}

Although severe secondary hyperthyroidism may result in growth arrest, only a weak association between parathyroid hormone $(\mathrm{PTH})$ values and linear growth was reported in children with $\mathrm{CKD}$ and recommended CKD-stage dependent PTH target ranges differ widely $(31,32)$. "In general, minimal PTH suppressive calcitriol dosages should be used in order to keep PTH levels within the desired target range" (22). "Supplementation with cholecalciferol or ergocalciferol should be initiated in children with serum 25-hydroxyvitamin D concentrations below $75 \mathrm{nmol} / \mathrm{L}(<30 \mathrm{ng} / \mathrm{mL})$ ” (23).

\section{Physical Activity}

Physical activity is often reduced in children with CKD and is associated with abnormalities in serum markers of bone formation and remodeling (33). Although endurance exercise improves bone formation in subtotal nephrectomized young rats (34), studies demonstrating better growth after increased physical activity in children with CKD are lacking.

\section{Treatment of Renal Anemia}

Although longstanding anemia in pediatric CKD patients may result in anorexia and catabolism, its impact on growth is small but should nevertheless be treated to improve overall well-being, physical capacity and cardiovascular health $(19,35,36)$.

\section{Growth Hormone Treatment}

Treatment with recombinant human growth hormone (rhGH) is a measure proven to improve adult height in short children with CKD (13). The positive results from initial clinical trials have been confirmed by several large, prospective, observational studies and registries, underlining the importance of its use in this population in order to improve growth outcome $(19,37-$ 41). Clinical practice recommendations for the use of $\mathrm{rhGH}$ in pediatric CKD patients have been provided by expert committees $(13,42)$. Infancy and early childhood are the most sensitive phases for the growth-suppressing effects of CKD which is at least partly related to GH insensitivity. Any impairment of height velocity during these phases may result in profound growth retardation. In addition, catch-up growth after correction of reversible causes of growth failure and initiation of other measures, including rhGH, may not be complete with the potential consequence of irreversible loss of growth potential (13). RhGH induced catch-up growth is positively associated with estimated glomerular filtration, mid-parental height, initial target height deficit and duration of rhGH therapy, and negatively correlated with patient age $(8,43-45)$. "Therefore, rhGH should be initiated as soon as growth retardation becomes evident" (13).

The presence of open epiphysis on the X-ray of the left wrist indicates growth potential, which is a prerequisite for the indication of rhGH treatment in children presenting with persistent short stature (13). "Children above 6 months of age with stages 3-5 CKD or on dialysis should be candidates for rhGH therapy if they have persistent growth failure-defined as a height below the 3rd percentile for age and sex, and a height velocity below the 25 th percentile-once other potentially treatable risk factors for growth failure have been adequately addressed and provided the child has growth potential" (13). "RhGH therapy should also be considered for children with stages 3-5 CKD or on dialysis aged above 6 months who present with a height between the $3 \mathrm{rd}$ and 10 th percentile, but with persistent low height velocity ( $<25$ th percentile), once other potentially treatable risk factors for growth failure have been adequately addressed" (13). "Such early, preventive therapy is probably more cost-effective than starting at a more advanced age, when growth retardation has become more evident and higher absolute rhGH doses are required" (13). RhGH is substantially less effective in children requiring maintenance dialysis compared to children prior to dialysis. However, there is evidence that rhGH-induced catch-up growth can be markedly improved by intensified dialysis, e.g., by daily hemodialfiltration, which enhances dialytic clearance and thereby, probably, GH sensitivity $(28,46)$.

Children suffering from nephropathic cystinosis often show severe growth retardation despite somewhat mild reductions in GFR, which is thought to be related to the deleterious effects of Fanconi syndrome, resulting in hypophosphatemic rickets and malnutrition and/or an underlying obsteoblast/osteoclast defect (47). "Therefore, rhGH treatment is recommended in short children with nephropathic cystinosis in all stages of CKD" (47).

"Daily dosing is more effective than three doses per week and the optimal dose is $0.045-0.05 \mathrm{mg} / \mathrm{kg}$ body weight per day by subcutaneous injection in the evening" (13). "The primary treatment target should be to return the child's height to their individual genetic percentile channel" (13). "Treatment may be suspended once this target is reached, but growth should be further closely monitored" (13). "In rhGH treated patients with residual kidney function, rhGH should be continued after the initiation of dialysis, but stopped at the time of kidney transplantation" (13). "RhGH therapy should, however, subsequently also be considered for pediatric kidney transplant recipients for whom expected catch-up growth cannot be achieved by steroid minimization, or for patients in whom steroid withdrawal is not feasible due to high immunological risks, particularly in children with suboptimal graft function (GFR $<50 \mathrm{ml} / \mathrm{min} / 1.73 \mathrm{~m}^{2}$ ) (vide infra)" (13). "Growth should be monitored for at least 1 year post-transplantation before rhGH therapy is considered, in order to allow for spontaneous catch-up growth without the use of rhGH therapy" (13).

\section{Transplantation}

Kidney transplantation corrects many of the metabolic and endocrine disorders contributing to uremic growth failure. 
However, catch-up growth after kidney transplantation occurs far from regularly and is usually only noted in young children (48). Apart from transplant function, age and extent of growth retardation at the time of transplantation, in addition to corticosteroid dosage, are inversely correlated with growth rates after transplantation. Late steroid withdrawal in patients treated with a combination of a calcineurin inhibitor and mycophenolate mofetil resulted in improved growth rates in steroid-free patients compared to controls, which was not associated with increased rejection rates (49). However, substantial catch-up growth was noted in prepubertal patients only.

It is reasonable to assume that an early steroid-withdrawal, or even complete steroid-avoidance, will result in better growth outcome. In line with this, a retrospective analysis of posttransplant growth in 74 pediatric patients who had been weaned off steroids within 6 months of transplantation showed remarkable findings (4). Normal adult height ( $>-2$ SD) was achieved in 94 and $80 \%$ of prepubertal and pubertal patients, respectively. Similarly, early steroid-withdrawal ( $<6$ weeks) and complete steroid avoidance was shown to be safe and resulted in a height increment of $\sim 1$ SDS within 3-5 years after kidney transplantation (50-53). There is evidence that leg length is more reduced than trunk length in children requiring kidney replacement therapy, resulting in disproportionate stunting (39). Therefore, it is important to note that kidney transplantation results in preferential stimulation of leg growth in these patients and is thereby able to completely normalize body proportions by adulthood, if the transplant is performed before puberty

\section{REFERENCES}

1. Harambat J, Bonthuis M, van Stralen KJ, Ariceta G, Battelino N, Bjerre A, et al. Adult height in patients with advanced CKD requiring renal replacement therapy during childhood. Clin J Am Soc Nephrol. (2014) 9:929. doi: $10.2215 / C J N .00890113$

2. Gil S, Aziz M, Adragna M, Monteverde M, Belgorosky A. Nearadult height in male kidney transplant recipients started on growth hormone treatment in late puberty. Pediatr Nephrol. (2018) 33:17580. doi: $10.1007 / \mathrm{s} 00467-017-3777-2$

3. Fine RN, Martz K, Stablein D. What have 20 years of data from the North American Pediatric Renal Transplant Cooperative Study taught us about growth following renal transplantation in infants, children, and adolescents with end-stage renal disease? Pediatr Nephrol. (2010) 25:73946. doi: 10.1007/s00467-009-1387-3

4. Klare B, Montoya CR, Fischer DC, Stangl MJ, Haffner D. Normal adult height after steroid-withdrawal within 6 months of pediatric kidney transplantation: a 20 years single center experience. Transpl Int. (2012) 25:276-82. doi: 10.1111/j.1432-2277.2011. 01400.x

5. Franke D, Winkel S, Gellermann J, Querfeld U, Pape L, Ehrich JH, et al. Growth and maturation improvement in children on renal replacement therapy over the past 20 years. Pediatr Nephrol. (2013) 28:2043-51. doi: 10.1007/s00467-013-2502-z

6. Andre JL, Bourquard R, Guillemin F, Krier MJ, Briancon S. Final height in children with chronic renal failure who have not received growth hormone. Pediatr Nephrol. (2003) 18:685-91. doi: 10.1007/s00467-0031145 - $\mathrm{x}$

7. Englund MS, Tyden G, Wikstad I, Berg UB. Growth impairment at renal transplantation-a determinant of growth and final height. Pediatr Transplant. (2003) 7:192-9. doi: 10.1034/j.1399-3046.2003.00068.x
(54). Thus, efforts to avoid a substantial height deficit before transplantation, through the use of rhGH treatment, early (preemptive) renal transplantation, and immunosuppressive strategies characterized by the early withdrawal, or even complete avoidance of glucocorticoid medication, should be undertaken to improve growth outcome and normalize body proportions in pediatric renal allograft recipients.

\section{CONCLUSIONS}

Early diagnosis and adequate management of growth failure is of the utmost importance in children with CKD. The main measures are (i) preservation of kidney function by using renin-angiotensin aldosterone system inhibitors (RAAS), (ii) ensuring adequate energy intake, (iii) correction of acidosis and electrolyte imbalances, (iv) initiation of $\mathrm{rhGH}$ treatment in case of persistent growth failure, and (v) the provision of adequate dialysis in children on maintenance dialysis. Finally, as with any child with end-stage CKD, the ultimate goal is to perform (preemptive) kidney transplantation, in order to avoid the growth-suppressing effects of longterm dialysis and to provide enough GFR to allow for adequate growth.

\section{AUTHOR CONTRIBUTIONS}

The author confirms being the sole contributor of this work and has approved it for publication.
8. Haffner D, Schaefer F, Nissel R, Wuhl E, Tonshoff B, Mehls O. Effect of growth hormone treatment on the adult height of children with chronic renal failure. German Study Group for growth hormone treatment in chronic renal failure. N Engl J Med. (2000) 343:923-30. doi: 10.1056/NEJM200009283431304

9. Al-Uzri A, Matheson M, Gipson DS, Mendley SR, Hooper SR, Yadin $\mathrm{O}$, et al. The impact of short stature on health-related quality of life in children with chronic kidney disease. J Pediatr. (2013) 163:73641.e1. doi: 10.1016/j.jpeds.2013.03.016

10. Wong CS, Gipson DS, Gillen DL, Emerson S, Koepsell T, Sherrard DJ, et al. Anthropometric measures and risk of death in children with end-stage renal disease. Am J Kidney Dis. (2000) 36:811-9. doi: 10.1053/ajkd.2000.17674

11. Furth SL, Stablein D, Fine RN, Powe NR, Fivush BA. Adverse clinical outcomes associated with short stature at dialysis initiation: a report of the North American Pediatric Renal Transplant Cooperative Study. Pediatrics. (2002) 109:909-13. doi: 10.1542/peds.109.5.909

12. Ku E, Fine RN, Hsu CY, McCulloch C, Glidden DV, Grimes B, et al. Height at First RRT and mortality in children. Clin J Am Soc Nephrol. (2016) 11:832-9. doi: 10.2215/CJN.08250815

13. Drube J, Wan M, Bonthuis $M$, Wühl E, Bacchetta J, Santos F, et al. Clinical practice recommendations for growth hormone treatment in children with chronic kidney disease. Nat Rev Nephrol. (2019) 15:57789. doi: 10.1038/s41581-019-0161-4

14. Franke D, Alakan H, Pavicic L, Gellermann J, Muller D, Querfeld U, et al. Birth parameters and parental height predict growth outcome in children with chronic kidney disease. Pediatr Nephrol. (2013) 28:233541. doi: 10.1007/s00467-013-2604-7

15. Mehls O, Wuhl E, Tonshoff B, Schaefer F, Nissel R, Haffner D. Growth hormone treatment in short children with chronic kidney disease. Acta Paediatr. (2008) 97:1159-64. doi: 10.1111/j.1651-2227.2008.00845.x

16. Silverstein DM. Growth and nutrition in pediatric chronic kidney disease. Front Pediatr. (2018) 6:205. doi: 10.3389/fped.2018.00205 
17. Rees L, Schaefer F, Schmitt CP, Shroff R, Warady BA. Chronic dialysis in children and adolescents: challenges and outcomes. Lancet Child Adolesc Health. (2017) 1:68-77. doi: 10.1016/S2352-4642(17)30018-4

18. Nissel R, Brazda I, Feneberg R, Wigger M, Greiner C, Querfeld U, et al. Effect of renal transplantation in childhood on longitudinal growth and adult height. Kidney Int. (2004) 66:792-800. doi: 10.1111/j.1523-1755.2004.00805.x

19. Behnisch R, Kirchner M, Anarat A, Bacchetta J, Shroff R, Bilginer $\mathrm{Y}$, et al. Determinants of statural growth in european children with chronic kidney disease: findings from the cardiovascular comorbidity in children with chronic kidney disease (4C) study. Front Pediatr. (2019) 7:278. doi: 10.3389/fped.2019.00278

20. Tonshoff B, Cronin MJ, Reichert M, Haffner D, Wingen AM, Blum WF, et al. Reduced concentration of serum growth hormone $(\mathrm{GH})$-binding protein in children with chronic renal failure: correlation with GH insensitivity. The European Study Group for Nutritional Treatment of Chronic Renal Failure in Childhood. The German Study Group for Growth Hormone Treatment in Chronic Renal Failure. J Clin Endocrinol Metab. (1997) 82:100713. doi: 10.1210 /jcem.82.4.3893

21. Shaw V, Polderman N, Renken-Terhaerdt J, Paglialonga F, Oosterveld M, Tuokkola J, et al. Energy and protein requirements for children with CKD stages 2-5 and on dialysis-clinical practice recommendations from the Pediatric Renal Nutrition Taskforce. Pediatr Nephrol. (2020) 35:51931. doi: 10.1007/s00467-019-04426-0

22. Shroff R, Wan M, Nagler EV, Bakkaloglu S, Cozzolino M, Bacchetta J, et al. Clinical practice recommendations for treatment with active vitamin $\mathrm{D}$ analogues in children with chronic kidney disease Stages 2-5 and on dialysis. Nephrol Dial Transplant. (2017) 32:1114-27. doi: 10.1093/ndt/gfx080

23. Shroff R, Wan M, Nagler EV, Bakkaloglu S, Fischer DC, Bishop N, et al. Clinical practice recommendations for native vitamin $\mathrm{D}$ therapy in children with chronic kidney disease Stages 2-5 and on dialysis. Nephrol Dial Transplant. (2017) 32:1098-113. doi: 10.1093/ndt/gfx065

24. Lurbe E, Agabiti-Rosei E, Cruickshank JK, Dominiczak A, Erdine S, Hirth A, et al. 2016 European Society of Hypertension guidelines for the management of high blood pressure in children and adolescents. J Hypertens. (2016) 34:1887-920. doi: 10.1097/HJH.0000000000001039

25. van den Belt, S M, Heerspink HJL, Gracchi V, de Zeeuw D, Wuhl E, et al. Early proteinuria lowering by angiotensin-converting enzyme inhibition predicts renal survival in children with CKD. J Am Soc Nephrol. (2018) 29:222533. doi: 10.1681/ASN.2018010036

26. van den Belt, S M, Heerspink HJL, Kirchner M, Gracchi V, Thurn-Valsassina $\mathrm{D}$, et al. Discontinuation of RAAS inhibition in children with advanced CKD. Clin J Am Soc Nephrol. (2020) 15:625-32. doi: 10.2215/CJN.09750819

27. Fischbach M, Zaloszyc A, Laetitia H, Menouer S, Terzic J. Why does three times per week hemodialysis provide inadequate dialysis for children? Hemodial Int. (2014) 18 (Suppl. 1):S39-42. doi: 10.1111/hdi.12222

28. Fischbach M, Terzic J, Menouer S, Dheu C, Seuge L, Zalosczic A. Daily on line haemodiafiltration promotes catch-up growth in children on chronic dialysis. Nephrol Dial Transplant. (2010) 25:867-73. doi: 10.1093/ndt/gfp565

29. Shroff R, Smith C, Ranchin B, Bayazit AK, Stefanidis CJ, Askiti V, et al. Effects of hemodiafiltration versus conventional hemodialysis in children with ESKD: the HDF, Heart and Height Study. J Am Soc Nephrol. (2019) 30:678-91. doi: 10.1681/ASN.2018100990

30. Rodig NM, McDermott KC, Schneider MF, Hotchkiss HM, Yadin O, Seikaly MG, et al. Growth in children with chronic kidney disease: a report from the Chronic Kidney Disease in Children Study. Pediatr Nephrol. (2014) 29:1987-95. doi: 10.1007/s00467-014-2812-9

31. Haffner D, Leifheit-Nestler M. Treatment of hyperphosphatemia: the dangers of aiming for normal PTH levels. Pediatr Nephrol. (2020) 35:48591. doi: 10.1007/s00467-019-04399-0

32. Bacchetta J. Treatment of hyperphosphatemia: the dangers of high PTH levels. Pediatr Nephrol. (2020) 35:493-500. doi: 10.1007/s00467-019-04400-w

33. Doyon A, Fischer DC, Bayazit AK, Canpolat N, Duzova A, Sozeri B, et al. Markers of bone metabolism are affected by renal function and growth hormone therapy in children with chronic kidney disease. PLoS ONE. (2015) 10:e0113482. doi: 10.1371/journal.pone.0113482

34. Troib A, Guterman M, Rabkin R, Landau D, Segev Y. Endurance exercise and growth hormone improve bone formation in young and growth-retarded chronic kidney disease rats. Nephrol Dial Transplant. (2016) 31:12709. doi: 10.1093/ndt/gfv373

35. Boehm M, Riesenhuber A, Winkelmayer WC, Arbeiter K, Mueller T, Aufricht C. Early erythropoietin therapy is associated with improved growth in children with chronic kidney disease. Pediatr Nephrol. (2007) 22:118993. doi: 10.1007/s00467-007-0472-8

36. Levin A, Stevens PE. Summary of KDIGO 2012 CKD Guideline: behind the scenes, need for guidance, and a framework for moving forward. Kidney Int. (2014) 85:49-61. doi: 10.1038/ki.2013.444

37. Akchurin OM, Schneider MF, Mulqueen L, Brooks ER, Langman CB, Greenbaum LA, et al. Medication adherence and growth in children with CKD. Clin J Am Soc Nephrol. (2014) 9:1519-25. doi: 10.2215/CJN.01 150114

38. Akchurin OM, Kogon AJ, Kumar J, Sethna CB, Hammad HT, Christos PJ, et al. Approach to growth hormone therapy in children with chronic kidney disease varies across North America: the Midwest Pediatric Nephrology Consortium report. BMC Nephrol. (2017) 18:181-017. doi: 10.1186/s12882-0170599-1

39. Rees L, Azocar M, Borzych D, Watson AR, Buscher A, Edefonti A, et al. Growth in very young children undergoing chronic peritoneal dialysis. J Am Soc Nephrol. (2011) 22:2303-12. doi: 10.1681/ASN.20100 20192

40. Zivicnjak M, Franke D, Filler G, Haffner D, Froede K, Nissel R, et al. Growth impairment shows an age-dependent pattern in boys with chronic kidney disease. Pediatr Nephrol. (2007) 22:420-9. doi: 10.1007/s00467-0060345-6

41. Franke D, Steffens R, Thomas L, Pavicic L, Ahlenstiel T, Pape L, et al. Kidney transplantation fails to provide adequate growth in children with chronic kidney disease born small for gestational age. Pediatr Nephrol. (2017) 32:511-9. doi: 10.1007/s00467-016-3503-5

42. Mahan JD, Warady BA, Consensus Committee. Assessment and treatment of short stature in pediatric patients with chronic kidney disease: a consensus statement. Pediatr Nephrol. (2006) 21:917-30. doi: 10.1007/s00467-006-0020-y

43. Nissel R, Lindberg A, Mehls O, Haffner D. Pfizer International Growth Database (KIGS) International Board. Factors predicting the nearfinal height in growth hormone-treated children and adolescents with chronic kidney disease. J Clin Endocrinol Metab. (2008) 93:1359-65. doi: 10.1210/jc.2007-2302

44. Haffner D, Wuhl E, Schaefer F, Nissel R, Tonshoff B, Mehls O. Factors predictive of the short- and long-term efficacy of growth hormone treatment in prepubertal children with chronic renal failure. The German Study Group for Growth Hormone Treatment in Chronic Renal Failure. J Am Soc Nephrol. (1998) 9:1899-907.

45. Mehls O, Lindberg A, Nissel R, Haffner D, Hokken-Koelega A, Ranke MB. Predicting the response to growth hormone treatment in short children with chronic kidney disease. J Clin Endocrinol Metab. (2010) 95:68692. doi: 10.1210/jc.2009-1114

46. Fischbach M, Fothergill H, Seuge L, Zaloszyc A. Dialysis strategies to improve growth in children with chronic kidney disease. J Ren Nutr. (2011) 21:436. doi: 10.1053/j.jrn.2010.10.022

47. Hohenfellner K, Rauch F, Ariceta G, Awan A, Bacchetta J, Bergmann C, et al. Management of bone disease in cystinosis: statement from an international conference. J Inherit Metab Dis. (2019) 42:1019-29. doi: 10.1002/jimd.12134

48. Laster ML, Fine RN. Growth following solid organ transplantation in childhood. Pediatr Transplant. (2014) 18:134-41. doi: 10.1111/petr.12219

49. Hocker B, Weber LT, Feneberg R, Drube J, John U, Fehrenbach H, et al. Improved growth and cardiovascular risk after late steroid withdrawal: 2-year results of a prospective, randomised trial in paediatric renal transplantation. Nephrol Dial Transplant. (2010) 25:617-24. doi: 10.1093/ndt/gfp506

50. Sarwal MM, Ettenger RB, Dharnidharka V, Benfield M, Mathias R, Portale A, et al. Complete steroid avoidance is effective and safe in children with renal transplants: a multicenter randomized trial with three-year follow-up. Am J Transplant. (2012) 12:2719-29. doi: 10.1111/j.1600-6143.2012.04145.x

51. Delucchi A, Valenzuela M, Lillo AM, Guerrero JL, Cano F, Azocar M, et al. Early steroid withdrawal in pediatric renal transplant: five years of follow-up. Pediatr Nephrol. (2011) 26:2235-44. doi: 10.1007/s00467-011-1934-6 
52. Webb NJ, Douglas SE, Rajai A, Roberts SA, Grenda R, Marks SD, et al. Corticosteroid-free kidney transplantation improves growth: 2-year follow-up of the TWIST randomized controlled trial. Transplantation. (2015) 99:117885. doi: 10.1097/TP.0000000000000498

53. Grenda R, Watson A, Trompeter R, Tonshoff B, Jaray J, Fitzpatrick M, et al. A randomized trial to assess the impact of early steroid withdrawal on growth in pediatric renal transplantation: the TWIST study. Am J Transplant. (2010) 10:828-36. doi: 10.1111/j.1600-6143.2010.03047.x

54. Franke D, Thomas L, Steffens R, Pavicic L, Gellermann J, Froede K, et al. Patterns of growth after kidney transplantation among children with ESRD. Clin J Am Soc Nephrol. (2015) 10:127-34. doi: 10.2215/CJN.02180314
Conflict of Interest: The author declares that the research was conducted in the absence of any commercial or financial relationships that could be construed as a potential conflict of interest.

Copyright (c) 2020 Haffner. This is an open-access article distributed under the terms of the Creative Commons Attribution License (CC BY). The use, distribution or reproduction in other forums is permitted, provided the original author(s) and the copyright owner(s) are credited and that the original publication in this journal is cited, in accordance with accepted academic practice. No use, distribution or reproduction is permitted which does not comply with these terms. 